\title{
On Higher Education
}

Transformation

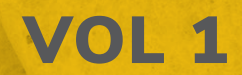

\section{SCHOLARLY \\ ENGAGEMENT AND \\ DECOLONISATION}

Editors:

M Crul, L Dick, H Ghorashi \& A Valenzuela Jr

Views from South Africa,

The Netherlands and the United States 


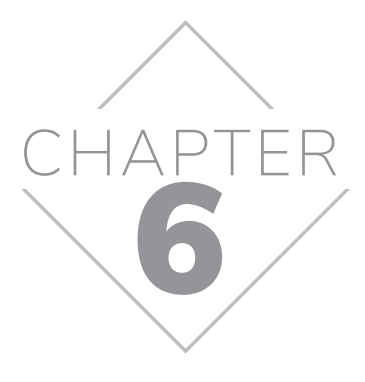

Decolonising research methods

\author{
Ideas on scholarship and \\ epistemic integrity
}

Nadira Omarjee

\begin{abstract}
With the South African decolonial student movement \#RhodesMustFall (RMF) at the University of Cape Town (UCT), South Africa pushed its university administration to rethink inclusivity and institutional racism, calling for a decolonisation of the curricula. RMF focused on post-apartheid South Africa's lack of restorative justice, challenging the logics of coloniality perpetuated in the curricula, as well as financial constraints impeding access to education. The conversations with RMF activists were about learning through sharing, requiring a process of self-reflexivity and an open-endedness to how we approach critical thinking and education. This was particularly important for considerations of a decolonised self. Thus, a methodology specific to the conversations was developed and called Agential Reflexive Methodology (ARM), relying on open notebook conversations $(O N C)$ and video conversations (VC).
\end{abstract}

Keywords: agential reflexive methodology (ARM); open notebook conversation (ONC); video conversation (VC); decolonised self; conversation; reflexivity; intersubjective 


\section{SCHOLARLY ENGAGEMENT AND DECOLONISATION}

\section{INTRODUCTION}

The objective of this chapter is to understand the context of conducting research amongst a vulnerable group, \#RhodesMustFall (RMF) activists at the University of Cape Town (UCT). The RMF movement has been stigmatised (Xaba, 2017) by scholars and the media for protesting neoliberalism and the lack of decolonisation. Their protests highlighted racial inequality with high levels of poverty amongst blacks, ${ }^{1}$ together with a lack of accessibility to higher education institutions. RMF drew attention to the exploitative practice of outsourcing ${ }^{2}$ by emphasising the fact that non-academic staff were not being paid a livingwage and, thus their children were unable to access higher education.

Conversations with primarily two key participants, Alex Hotz and Brian Kamanzi, from RMF had me rethinking the relationship between the researcher and the participant, as well as lived experiences of marginalised people and, the impact that has on co-producing knowledge. I looked to Paulo Freire (1970) for answers. Freire explains the need for a critical pedagogy that requires a dialogue between scholars so that the teacher is not perpetuating a system of domination (Haraway, 2004) through the banking model of education (Freire, 1970). Instead the student's lived experience is also brought into the classroom and recognised as a body of knowledge for the production of knowledge. Freire's thesis repositions the oppressed centrally, and through conscientisation (McNeil, 1993) the conversation is redirected, disrupting the power/knowledge nexus (Foucault, 1977). Lessons learnt from these conversations offer a way in which to rethink research methodology, as well as pedagogy with a particular focus on decolonisation.

As part of the conversation, Agential Reflexive Methodology (ARM) was developed as participant-based research, including the researcher an agent in co-producing knowledge (Freire, 1970; Foucault, 1977). Selfreflexivity (Harding, 1992) and conscientisation were employed as tools. The conversations were open-ended and revisited in follow-up conversations. Insights were gained through differing perspectives, and positions shifted

1 Black is political identity in South Africa. It was coined during apartheid and included, Indians, Coloureds and Africans (anyone who was not considered white).

2 Outsourcing refers to the practice of sub-contracting university workers with them not being paid a living wage. A distinction is made between workers and academics. Workers refers to people that clean, feed and provide security at South Africa's tertiary institutions. 
during the conversations. To this extent, the conversations, as part of ARM, offer an alternate perspective for engaging and dealing with issues around integration, inclusivity, relevance and curricula development for decolonising the academy.

\section{FRAMING THE CONTEXT}

Twenty-five years post-apartheid and South Africa is still facing challenges in dealing with issues around integration and poverty eradication. These issues are not separate from the academy and intersect through student population, curricula development and neoliberal policies (Mountz, 2015). Understanding how historical injustices affect current realities is a challenge that needs to be met with decisive action in order to make post-apartheid South Africa inclusive and representative.

In March 2015, RMF led protests at UCT and occupied the administration buildings. RMF was successful in initiating a nationwide student protest in October 2016 and insourcing all UCT workers by 2019. The South African student movements (read here as Fallisms, RMF and \#FeesMustFall [FMF)]) all share the same vision, 'putting the last first' (ONC [open notebook conversations], Leigh-Ann Naidoo, 26 January 2016; ONC, Alex Hotz, 29January 2016) which has aligned them in the struggle for free quality decolonised education and an end to outsourcing. On 16 February 2016, UCT tore down an RMF installation called Shackville. ${ }^{3}$ Students were brutalised and arrested. Shackville's aim was to bring to the foothills of UCT the reality that the majority of South Africans (black Africans) live below the poverty line. Moreover, Shackville highlighted the plight of black students seeking accommodation in Cape Town, either through lack of funds or by racist attitudes that prevent black students from living in formerly white areas. ${ }^{4}$ During the Shackville police clash, paintings from a nearby residence were burned and the ViceChancellor's office was petrol bombed.

3 See http://bit.ly/2O2O1Bt

4 UCT was a former white liberal institution and is thus located in upper-middle-class white neighbourhoods. 


\section{SCHOLARLY ENGAGEMENT AND DECOLONISATION}

Media representations of RMF have been ambiguous. Some portrayed a sympathetic view of RMF, whilst others have demonised the students and misrepresented the issues raised (Omarjee, 2016). To this extent, an important consideration in the research was the need to maintain the integrity of student voices. ${ }^{5}$ Thus, video conversations were conducted. These conversations are between various student groups such as RMF and FMF, as well as intergenerational. The research has been participatory, reflexive and self-representational, ensuring transparency and fostering trust. During the conversations, meaning was produced through political education, consciousness-raising and critical evaluation (McNeil, 1993). The intention with the conversations was to remove hierarchical binaries by speaking candidly to issues and, by flattening the structural relationship between the researcher and the participant.

\section{BECOMING A PARTICIPANT IN THE RESEARCH}

I am a decolonial feminist scholar, proposing mutual recognition (recognition of self and other) and a decolonised self as a means to challenge and resist the logics of coloniality. Decolonisation is therefore understood as challenging the logics of coloniality through material and intrapsychic circumstances (Omarjee, 2018). Teun van Dijk (1997:20-21) claims that "critical scholars make their social and political position explicit: they take sides, and actively participate in order to uncover, demystify or otherwise challenge dominance with their discourse analyses." When I arrived at UCT in January 1991, I was met by the Rhodes statue. This scene told me and others like myself (blacks) that we were all misplaced. But which places did black bodies have in a transitioning South Africa? Which places were ours to occupy? The feeling of being the subaltern and having the normalisation of whiteness imposed upon me brought with it the violence of a system that misplaced me (always looking for a place of belonging for my body [Ahmed, 2004]). Fixing me in the position of the subaltern meant I could never truly be at home within the white liberal academy. When Rhodes fell, I felt vindicated for the years of violence that my body had endured and the internal struggles of wanting to belong in a hostile environment that was clearly tolerating my presence. Therefore, my goal with the research was to affect change (decolonisation of self) through preserving the epistemic integrity of the voices of the participants. 
Rethinking the idea of the conversation against a top-down researcher/ researched power dynamic meant that I had to rethink research in order not to perpetuate the logics of coloniality by objectifying the participant. Instead the programme of decolonisation opened for review the way we think of ourselves in these positions as researcher or participant (Smith,1999). Nothing was fixed. As a result, I understood that my own investment in the research required a shift in how to conduct this particular research. I was not outside the research (Ibid.). The research was neither an object. Instead this was intersubjective research (Cook, 2009; Banks, et al., 2013; Shuttleworth, 2004), requiring a shift in how conversations were conducted as opposed to key informant interviews. Therefore, for me, engaging in the conversation from an intergenerational perspective created solidarity and a shared experience with the students from RMF. It was a bond that was forged based on the violence done unto us - black bodies in white spaces.

I realised my participation in the conversation was also part of my trauma mastery. It gave me a newfound enthusiasm for the research and for my participation. It allowed me to move beyond the power/knowledge nexus of the voyeuristic researcher towards an investment in the conversation as a way of conscientisation, leading to my own need to decolonise the self. The students knew this investment, and in a way their generosity with their time and their trust helped me to navigate these new understandings in an explorative and gentle manner. Even though I directed the initial question, I was allowing myself to be part of the process of conscientisation and, simultaneously, I was allowing the conversation to become the medium for conscientisation. Thus, the conversation became the space for allowing new ideas and new ways of knowing, being and becoming to unfold (Mupotsa, 2017; Mignolo, 2009). In this sense, the conversation was key for practicing decolonising the space and in rethinking decolonising research, disrupting subject/object relationships. I am deeply indebted to the participants in the conversations for my own understandings of decolonisation in the material and intrapsychic realms.

\section{UNDERSTANDING DECOLONISATION}

For the purposes of this research, the process of decolonisation is: firstly, to understand the effects and affects of colonisation and, secondly, to undo the 


\section{SCHOLARLY ENGAGEMENT AND DECOLONISATION}

effects and affects of colonisation. Sabelo Ndlovu-Gatsheni (2015:23) explains: "Decoloniality is ranged against imperialism, colonialism and coloniality as a constituent part of the modernist politics of dismemberment, alienation, exploitation and alterity. At the centre of decoloniality is the idea of remaking the world such that the enslaved, colonised, and exploited peoples can regain their ontological density, voice, land, history, knowledge and power." It follows from this that the perpetuation of coloniality persists through the "cultural archive” (Wekker, 2016). The cultural archive, according to Gloria Wekker, is about re-inscribing the binary relationship between the coloniser and the subaltern, "the cultural archive, and what it tells us about the continuities of the imperial construction of a dominant white Dutch self and the implicit or explicit way in which whiteness is bound up with it" (Ibid.:74).

Wekker infers that decolonisation is a response to the cultural archive, challenging the binary of the coloniser and the subaltern. From a Fanonian (1961) perspective, decolonisation read against the cultural archive is about understanding the violence implicit in the binary of the coloniser and the subaltern. Moreover, in a complementary reading of Fanon (1961) and wa Thiong'o (2006), violence can be interpreted as undoing the systemic violence of coloniality (the cultural archive), and notions of self (subaltern) that must be radically purged for the decolonised self to emerge. Thus, violence can be read as an unlearning/undoing of processes of subjugation that the subaltern has internalised in order for a decolonised self to emerge.

Decolonisation is then a response to the violent act of colonisation, replacing the 'old' cultural archive with new ways of being and becoming to unfold. Patrick Bond (2015) argues that South Africa has not shifted systemically. Instead South Africa has entrenched inequality through brazen neoliberal policies, implying that the cultural archive flourishes both on material and intrapsychic levels when decolonisation has been hindered. Therefore, for South Africa, decolonisation is an urgent response for shifting the cultural archive of coloniality and apartheid in the relationship between whites and blacks.

Wekker (2016:165) continues to argue that the historical systemic injustices of coloniality and the cultural archive perpetuated "the violence that was visited on black people overseas went unregistered, was obfuscated and disavowed." 
Wekker is referring to the relationship between the metropolis (Europe/ the West) and the colony. Her argument is crucial for rethinking curricula development and the rewriting of history from a decolonised perspective because as James Baldwin (2017:107) claimed,

History is not the past.

It is the present.

We carry our histories with us.

We are our history.

If we pretend otherwise, we literally are criminals.

Understanding the cultural archive as an historical process puts forward questions of restorative justice, which is a significant part of the programme of decolonisation. In this context, material can be read as neoliberal policies and, intrapsychic can be read as the cultural archive with the binary of coloniser and subaltern. The critique is then about shifting this dynamic that exists in the material and intrapsychic realms of coloniality. It is about undoing the effects and affects of coloniality. The programme of decolonisation is thus twofold. It is especially important for histories of oppression that have been written onto black bodies inhabiting white academic spaces to decolonise the self and, thereby produce meanings and knowledge from our lived experiences (Smith, 1999).

\section{THE THEORY/METHODOLOGY NEXUS AND THE DEVELOPMENT OF AGENTIAL REFLEXIVE METHODOLOGY (ARM)}

In the famous Ngugi wa Thiong'o's (2006) dictum, "decolonising the mind before decolonising the space" illustrates the argument that decolonisation "is a struggle to regain lost subjecthood and eventually citizenship and to answer many other questions to do with being and humanism as politicised states of existence” (Ndlovu-Gatsheni, 2015:33-34). "Making ourselves subjects” (hooks, 1992) requires reversing the material/social and intrapsychic/psychological effect of colonisation. However, a precondition for making ourselves subject

6 Ngugi wa Thiong'o (1986) and Lacan (1977) argued that through language we come into being so that the language of the coloniser shapes our perceptions and affects our sense of self. Therefore, it is crucial to decolonise our minds in order to tackle decolonisation in other spheres. 


\section{SCHOLARLY ENGAGEMENT AND DECOLONISATION}

is recognition of self, leading to the possibility for mutual recognition. Plainly put, this means that in order to make ourselves the subject, we have to violently abandon an object position (violence refers to an intrapsychic process of splitting-off or separating from the coloniser's gaze ${ }^{7}$ that fixes the subaltern in an object position) and appropriate a subject position to recognise ourselves as subject/self. This is what I refer to as a process of decolonisation of the mind to become the decolonised self. ${ }^{8}$

Walter Mignolo (2009) talks about epistemic disobedience and recognises the lived experiences of the subaltern. The work of Wekker and feminist psychoanalysts (Benjamin, 1988; Flax, 1994) build onto the notion of sameness and difference ${ }^{9}$ whilst relating to Freire's (1970) understanding of praxis as a basis for curricula development in an intercultural society. Thus, the scholars used for this study build onto the notion that, for people to flourish in society we need to ensure conditions for mutual recognition so that differences can be learned as well as respected.

Academia can serve as a rehearsal space for new expressions of subjectivity, agency and a decolonised self. Decolonising academia is then a crucial project for disrupting and challenging the power/knowledge nexus of coloniality inherent in the curricula. Thus, the process in thinking through decolonisation is to deconstruct the past and reconstruct the present by making ourselves subject through curricula development. In the South African context, decolonisation of academia means access to the academy - for previously marginalised people in particular. Thereafter, affective engagement with epistemological projects for the decolonised self that help to rethink the power/knowledge nexus as well as the cultural archive of coloniality.

In the considerations for the development of ARM, participant engagement in conversation as a tool for conscientisation was the primary mode for pedagogy without hierarchy. There is no teacher/student relationship. Instead a shared

7 Gaze here refers to Laura Mulvey's (1989) work on the male gaze.

8 Decolonised self refers to a reclamation/appropriation of self after the advent of stripping subjectivity through colonialism and slavery. It is a term that borrows from feminist psychoanalysis and mutual recognition as an exit to the master/slave dialectic (Benjamin, 1988). 
understanding is about knowledge production through conversation. Notetaking became a primary source for marking data points in the conversation. ONCs and VCs (video conversations) were an innovative way of conducting transparent research. Participants were able to self-represent in note-taking, allowing the researcher and the participant to "affect each other mutually and continually” (Alvesson \& Skoldberg, 2001:39). My concern was to preserve the integrity of the voices of the participants as well as to foster trust.

I began each conversation by asking permission to take notes. ${ }^{10}$ Furthermore, I invited participants to look at and correct the notes if they were not satisfied with the notes. I did this by making the notebook visible in the conversation. With the VC, after the video was stopped, I invited participants to review my notes. This helped to encourage self-representation in the note-taking and to further foster trust. It was also a way in which to disrupt hierarchical positionings between the researcher and the participant. The participants were always in control of what was being written in the notebook. That said, I am aware that I was in control of the ONC in that I initiated the conversation and set the agenda (Freire, 1970) by directing the initial question for the conversation. This is different to the VC process because I did not intervene in the conversation. Those conversations were organic and flowed. In the VC, participants set the agenda for their conversations. I merely did the technical set-up and took notes during the VC.

In the ONC process, the transparency allowed for discussions on shared definitions of decolonisation. What I found was that the ONC was a process of disruption and, of sharing and learning. With each ONC I learned to see a different perspective. In my initial conversation with Brian Kamanzi of RMF, I was invited to think through an endgame for decolonisation and, thus I began to hold intergenerational conversations and became a participant in the research (ONC, Brian Kamanzi, 4 February 2016). Therefore, the research is not a linear process. Instead it is reflexive and intersubjective.

10 The ONC was primarily used to gain trust. Data markers were used to flag important moments in the conversation. This was because RMF at the time was highly stigmatised and branded as hooligans in the media. Therefore, many were guarded in talking to outsiders. There was also talk of them being followed by security agents and trust was a crucial consideration to establish the research. The research was therefore led by the students themselves. It was only later once trust was established that I was able to do VCs. Those too focused on historical processes of activism and inter-university cooperation for the student movements. The VCs are archived at the Mayibuye Centre at the University of the Western Cape, Cape Town, South Africa. 


\section{SCHOLARLY ENGAGEMENT AND DECOLONISATION}

Sandra Harding (1992:439) argued that "strong reflexivity as a main source of objectivity" opposes the idea of objective research since researchers are also affected by their situatedness. ARM allows for meaning-making through a gradual process of reflection and contextualisation. I was clear about my own historical situatedness. As a researcher I made it clear to the participants why I was invested in these conversations. I did this by stating the motivation for the research and that the purposes for conducting ARM was to encourage self-representation. I was aware that by stating my situatedness, I could have affected the content and responses from the participants. However, this helped with establishing more trusting and open exchanges in the conversations.

Crucial elements of ARM are voice and self-representation, allowing participants a measure of control in the conversation so that the research is a negotiated process of learning. Meaning-making is thus symptomatic of the conversation. Paulo Freire (1970:62) claimed that "students ... are now critical co-investigators in dialogue with the teacher... The role of the problem-posing educator is to create, together with the students, the conditions under which knowledge at the level of the doxa is superseded by true knowledge, at the level of the logos." I am not sure that I fully understand or agree with Freire's understanding of 'true knowledge', because all knowledge is given from a particular perspective, and much like truth there are many interpretations of knowledge systems or epistemology. However, the idea of co-producing knowledge of the oppressed through dialogue is appealing in that the power/knowledge nexus is critiqued. As such, ARM attempts to maintain centrality to dialogue as a way in which to disrupt dominant discourses.

The conversations were sometimes uncomfortable and awkward. In the intergenerational VC with Ahmed Kathrada ${ }^{11}$ on 20 August 2016, Simon Rakei from RMF respectfully disagrees with Kathrada about history. This is a crucial moment in the disjuncture between Rainbowism ${ }^{12}$ and Fallism ${ }^{13}$ whereby Simon sees erasures in a history that was the lived experience of Kathrada. Such moments in the conversations are seminal moments for not only research and pedagogy, but also the ways in which history is experienced and remembered.

11 Ahmed Kathrada was a Rivonia Trialist and was a political prisoner held on Robben Island with Nelson Mandela, Walter Sisulu, Goven Mbeki and others.

12 Rainbowism was Nelson Mandela's rhetoric on reconciliation.

13 Fallism refers to the decolonial student movements pushing back against rainbowism because reconciliation is not possible without decolonisation. 
This rethinking of history has also led participants to question my motivations leading me to clarify and restate my interest in the research, which helped in re-establishing trust.

Critical theory was contested in the conversations for under-utilising empirical evidence (Alvesson \& Skoldberg, 2001:133-139). Importance was placed on building new ways of thinking and reflecting (new knowledge systems), assisting in shifting beliefs and hegemonic positions or worldviews (Johnstone, 2002), in order to bring about necessary changes for making academia more accessible and relevant in epistemological explorations. Therefore, in the ONC, theoretical positions were not a given but were instead deconstructed and critically evaluated (Ibid.:243), further developing ARM. In this way, it was possible to shift language to reflect new possibilities for change, "The process of construction thus demands something to construct (out there, so long as we are not talking about pure objects of fantasy), a constructing subject (the researcher) and a social context that constructs the researcher (society, language, paradigms, the local research community). To put it simply: reflexivity, in the research context, means paying attention to these aspects without letting any one of them dominate" (Ibid.:246).

The methodology of the research was multipronged. It was based on reviewing current literature on decolonisation as well as analysing social media responses, ${ }^{14} \mathrm{ARM}$ and participant observation. Participant observation was also employed at an imbizo ${ }^{15}$ as a way of observing (Marshall \& Rossman, 1989) a gathering/meeting, as well as noting the social dynamics that occur in that space without impacting the event. However, this was not without its contradictions. At the imbizo at UCT on 1 February 2016, I was acknowledged by UCT management and was also introduced to members of RMF. Thus, my presence did not go unnoticed. However, I did not take notes during the imbizo and only when it seemed appropriate, did I take photos with my mobile phone of the banners and the gathering. I did not photograph workers when they spoke because of issues related to job security. Since the imbizo was public there were photographers from media houses and, thus my presence was not confrontational. The imbizo was a transparent meeting with an open microphone that allowed students, workers and management to engage in dialogue. 


\section{SCHOLARLY ENGAGEMENT AND DECOLONISATION}

To summarise, ARM is not a top-down approach with a research subject and a researched object. Instead ARM highlights a way of doing research that is more self-reflexive, intersubjective, inclusive, transparent, accountable and public. The way in which I tried to make the research transparent and accountable to the participants was to send versions of my writings to the participants especially the two key participants I have followed closely over the past years.

\section{CONVERSATION AS A TOOL FOR CONSCIENTISATION}

Freire (1970:73) explains the need for a critical pedagogy that requires dialogue between scholars: "Only dialogue, which requires critical thinking, is also capable of generating critical thinking." Thus, Freire demands of us to rethink knowledge production by breaking away from the perpetuation of systems of domination (banking model) that takes hold in the classroom. Freire, like Smith (1999), repositions the oppressed centrally so that conscientisation is brought to the lived experience of the oppressed.

Alvesson and Skoldberg (2001:38) argue that "exploring how the lifeworld emerges as a result of microprocesses in the form of social interactions, which generate the common-sense knowledge of the participants" highlights how the university gives meaning to lived experiences on campus and how that gets reflected in society in general. In that way, RMF offers an alternate perspective for engaging and dealing with issues around integration, inclusivity and relevance for marginalised communities because they locate self-determination and self-reliance as the cornerstone for rethinking the relationship to learning as part of the programme for decolonisation (ONC, Brian Kamanzi, 8 February 2016).

A strong sense of reflexivity in the form of ARM attempts to understand and explore how conversations on decolonisation can contribute towards a decolonised self. The theoretical and methodological frames intersect by way of understanding a decolonised self through decolonising research and pedagogy that is based on locating the oppressed central to scholarship. The theoretical framework highlights the ways in which decolonising curricula can facilitate the process of inclusion whilst free quality decolonised education can help materially towards accessibility to the university (ONC, Brian Kamanzi, 8 February 2016). The theoretical frame is thus explored in the conversation 
as praxis, with an exchange of ideas and learning, with the researcher as a participant in the research. For analysing ARM, discourse analysis and, in particular, textual analysis was employed.

Since the research is based on conversations, there was neither a beginning nor an end. Instead the conversation as a tool was part of a continuum in the practice of decolonising the self, which moreover became part of the reflexive aspect of conscientisation. Part of the function of the conversation was to explore themes, concepts, ideas, notions and principles that were open for critique or left to be considered further. This was demonstrated in the VC with Ahmed Kathrada when there is a clear disjuncture in the reflective moment of reading history. Furthermore, the common definitions and understandings that emerged during the conversations were heavily relied on because they were reached through consensus and agreement. However, these too were open for further review and change. The conversation as a function of data collection was fluid because as a researcher and a participant implicated in the conversations, definitions and meanings were sometimes misunderstood through intergenerational gaps. Sufficed to say, I learnt a lot of new words and concepts.

When reviewing the notes from the ONC and VC, the dominant method of interpretation was based on how meaning was produced during the conversations. These notes and conversations were revisited in the follow-up conversations to ensure that the meanings produced were shared meanings. The case of interpreting violence was one such example of how meanings were produced and shared. The conversation became the medium for consciousnessraising and critical awareness in how it was envisioned in Pedagogy of the Oppressed (Freire, 1970). For example, Alex Hotz speaks about Black Radical Feminism as a component of RMF (ONC, Alex Hotz, 29 January 2016). For her, patriarchy is the violence of a discourse of supremacy. To abandon discursive practices of supremacy, patriarchy has to be dismantled (ONC, Alex Hotz, 13 April 2016). She is critical of violence as a form of hyper-masculinity that is resistant to change. Yet she admits that with the amount of violence and silence around black womxn' ${ }^{16}$ bodies, "our ways of fighting have become characterised by hyper-masculinised, militarised forms of violences ... we 


\section{SCHOLARLY ENGAGEMENT AND DECOLONISATION}

embody the armed wing of liberation movements ... there are no safe spaces ... rape culture persists ... we must act, we must burn, we don't think about how we must act" (ONC, Alex Hotz, 23 December 2016). Alex is critical of how violence is used to justify an abuse of power in the form of systemic and institutional violences that are meted out daily, and that further alienates students at university and, in particular, womxn and black students. She talks about resistance to hyper-masculinity in the ways in which the Trans Collective disrupted the RMF exhibition at $\mathrm{CAS}^{17}$ from proceeding. This is a crucial moment for how womxn and trans people's actions impacted the conversations and how that helped in rethinking patriarchal displays of power. Therefore, meaning-making in the analysis of the ONCs and VCs are reflexive due to personal histories and, thus is context specific. ARM is about shared voices in the initial conversations, with Alex Hotz and Brian Kamanzi and, later with other RMF activists and stalwarts like Ahmed Kathrada, giving form to broader conversations. As a result of the two key participants, snowballing was used as a way of accessing other participants.

\section{DECOLONISING DISCOURSE - A STRATEGY FOR ANALYSING CONVERSATIONS}

Discourse is about power and normalisation. Michel Foucault (1977) argued that discourse was about imitation and through repetition (mainstreaming ideas, Van Zoonen, 1994) discourse becomes normalised. Moreover, the discourse of coloniality has been embedded in language so that the Lacanian dictum, "language speaks us" (Ibid.:13) becomes more about how we think of ourselves as subalterns. Barbara Johnstone (2002) claims that discourse contributes towards shaping our worldviews. Moreover, language and discourse are not static but are fluid and shifting (Foucault, 1977). Furthermore, discourse as an imitation of power, embedded in language, functions to perpetuate the coloniality of the mind and, thus the perpetuation of the cultural archive. Decolonising the mind through processes of conscientisation, such as ARM delink discursive practices of coloniality from the making of the subject. Implying that decolonisation is about the subaltern claiming agency to become the decolonised self through a critical examination of history and 
curricula. Therefore, undoing language through nuance reflects the process of being/becoming a decolonised self. Johnstone (Ibid.:228) further claims that "discourse is fundamentally the result of flexible strategies, not fixed rules: no interaction is exactly like any other, there is always another way of doing things, idiosyncrasy and novelty are always possible and usually interpretable". In the conversation with Alex Hotz on 23 December 2016, her reflections on how toxic masculinity enters feminist spaces and the need to be vigilant of such violence becoming normalised, is a crucial data marker for thinking through a decolonised self. Thus, understanding the lens (theoretical frame) from which analyses and interpretations were conducted became paramount for maintaining transparency and, an openness for critique and criticality, which was further explored in the conversations.

In the act of reading a social movement like RMF, the ways in which interpretation works becomes part of the project of criticality. However, the entrapment of any reading, including RMF, is that it is still a subjective process. In this chapter, I am the dominant voice. Analysis is subjective and this is by no means a reflection of the entirety of RMF, but a glimmer of some of the conversations that were happening at a particular moment in time with a particular group of people from that movement. Therefore, in reading the conversations that I participated in, means a narrow focus on subjective interpretations of the conversations as texts. Part of the challenge in reading conversations as texts is that identity is negotiated, shifting and infused in the symbolic imaginary of language (Žižek, 2006:18) so that we never stand outside language or the conversation as text. Instead we use language to disrupt normalising practices of coloniality. This also means that more radical voices within RMF are not reflected in this study.

For realising a decolonised self and understanding how language affects notions of identity, the conversation became a tool for self-actualisation. The attention to language for such purposes was to show how language shifts to achieve self-awareness. In the following conversation, the text attempted to highlight a level of transparency and accountability through a method of selfactualisation and self-reflection. Brian Kamanzi, in one of our conversations, spoke about the need to "push further beyond academia into community/ society, in particular as non-partisan” (VC, Brian Kamanzi \& Khadija Khan, 


\section{SCHOLARLY ENGAGEMENT AND DECOLONISATION}

2 June 2016). Brian was speaking about bridging the gap between academia and community. This notion was further explored in ideas of belonging; building on research and teaching that addresses real-life solutions so that the community is central to the project of education. To this extent, many RMF activists have graduated and gone on to work in NGOs such as Equal Education, Ndifuna Ukwazi ${ }^{18}$ (an urban land justice project) and various other community-driven projects. Brian himself is part of 'Pathways to Free Education, ${ }^{19}$ a forum that produces a publication, bridging the gap between the ivory tower, trade unions, and communities. He also hosted a programme on a community radio station that aimed to address social justice issues pertinent to low-income communities. He comments that power can be surprised through social consciousness programmes whereby disruptions function to pushback against the status quo. Gains are made through these constant moments of resistance (Ibid.).

Decolonising the self was used as a strategy to challenge hierarchical binary oppositions of race, class, gender, sexuality and dis/ability. The transparency of the method of interpretation is open-ended and can be critically evaluated by other scholars through reviewing the notebook. The VCs have been archived at the Mayibuye Centre at the University of the Western Cape, Cape Town, South Africa. The notebook is still under review for further research purposes and will be made available at the Mayibuye Centre at a later stage.

\section{CONCLUSION}

This chapter highlighted the method by which the conversation became reflexive, intersubjective, inclusive and transparent. It did this by showing how disrupting power relations between the researcher and the participant resists the logics of coloniality, allowing space for decolonising research methods by placing the researcher within the research as a participant so that the researcher was altered and affected by the research (intersubjective). This intersubjective aspect of the research method showed how the research is not an object. Instead the research is a subjective experience whereby the participants including the researcher are mutually affected through the process

18 See http://bit.ly/2SG2rdz

19 See http://bit.ly/2V7IMoz 
of the conversation. It relies heavily on Freire's (1970) understanding of Pedagogy of the Oppressed as a way of conscientisation and decolonising the mind.

The open-endedness of the conversation allows for fluidity by providing the space to rethink the objectives of the research. The conversation allows for contestation, meaning-making, subversion, resistance and disruption of the power/knowledge nexus as a way of shifting discursive practices of normalisation. The conversation then creates new spaces for reimagining a decolonised self through exploring fluid ways of subjectivity. The hope is that with ARM, the research will facilitate a shift towards decolonising the self through consciousness-raising and critical evaluation in the process of the conversation. The research is heavily reliant on feminist research methodologies such as situatedness and self-reflexivity as well as Pedagogy of the Oppressed, as a way in which to give voice to previously marginalised people with the encouragement of self-representation. This chapter hopes to have highlighted the ways in which meaning was given expression to in the context of the research. 


\section{SCHOLARLY ENGAGEMENT AND DECOLONISATION}

\section{REFERENCES}

\author{
Ahmed, S. 2004. The Cultural Politics \\ of Emotion. Edinburgh: Edinburgh \\ University Press.
}

Ahmed, S. 2006. Orientations: Towards a Queer Phenomenology. GLQ: A Journal of Lesbian and Gay Studies, 12(4):543-574. https://doi. org/10.1215/10642684-2006-002

Ahmed, S. 2007. A Phenomenology of Whiteness. Feminist Theory, 8(2):149-168. https://doi. $\mathrm{rg} / 10.1177 / 1464700107078139$

Alvesson, M. \& Skoldberg, K. 2001. Reflexive Methodology: New Vistas for Qualitative Research. London: SAGE Publications.

Banks, S.; Armstrong, A.; Carter, K.; Graham, H.; Hayward, P.; Henry, A.; Holland, T.; Holmes, C.; Lee, A.; McNulty, A.; Moore, N.; Nayling, N.; Stokoe, A. \& Strachan, A. 2013. Everyday ethics in community-based participatory research. Contemporary Social Science: Journal of the Academy of Social Sciences, 8(3):263-277. https:// doi.org/10.1080/21582041.2013.769618

Baldwin, J. 2017. I Am Not Your Negro. New York: Vintage Books.

Benjamin, J. 1988. Bonds of Love: Psychoanalysis, Feminism and the Problem of Domination.

New York: Pantheon.

Benjamin, J. 1995. Like Subjects, Love Objects. Essays on Recognition and Sexual Difference. New Haven: Yale University Press. pp.1-79.

Biko, S. 2004. I write what I like. Johannesburg: Picador Africa.
Bond, P. 2015. South African Student Protest: Decolonization, Race and Class Politics. Global Research. Available: http://bit.ly/2U2lGzh

Cammarota, J. 2011. The Value of a Multicultural and Critical Pedagogy: Learning Democracy Through Diversity and Dissent. Multicultural Perspectives, 13(2):62-69. https://doi.org/10.1080/1521 0960.2011 .571546

Cook, T. 2009. The purpose of mess in action research: building rigour though a messy turn. Educational Action Research, 17(2):277-291. https://doi.1080/09650790902914241

Derrida, J. 1978. Writing and Difference. A. Bass (tr.). London: Routledge.

Fanon, F. 2001. The Wretched of the Earth. London: Penguin. https://doi. org/10.1007/978-1-137-05194-3_4

Fanon, F. 2008. Black Skins White Masks. London: Pluto Books.

Flax, J. 1990. Thinking Fragments. Psychoanalysis, Feminism, and Postmodernism in the Contemporary West. Berkeley: University of California Press.

Flax, J. 1994. Disputed Essays on Psychoanalysis, Subjects Politics and Philosophy. London and New York: Routledge.

Freire, P. 1970. Pedagogy of the Oppressed. London: Penguin.

Freire, P. 1998. Pedagogy of Freedom: Ethics, Democracry and Civic Courage. Rowman and Littlefield: Oxford. 


\section{CHAPTER 6 Decolonising research methods}

Ghorashi, H. 2014. Routed Connections in Late Modern Times. In: U.M. Vieten (ed.), Revisiting I $M$ Young on democracy, inclusion and normalisation. Houndmills: Palgrave Pivot. pp.49-67. https://doi.org/10.1057/9781137440976_4

Gramsci, A. 1982. Selections from the Prison Books. London: Lawrence and Wishart.

Hall, S. 1989. Cultural Identity and Cinematic Representation. In: Third Scenario Cultural Identity. Framework, 36:68-81.

Haraway, D. 1991. 'Gender' for a Marxist Dictionary: The Sexual Politics of a Word. In: Simians, Cyborgs, and Women. The Reinvention of Nature. London: FAB. pp.127-148.

Haraway, D. 2004. The Haraway Reader. London: Routledege.

Harding, S. 1986. The Science Question in Feminism. Ithaca and London: Cornell University Press.

Harding, S. 1992. Rethinking standpoint epistemology: What is "strong objectivity?”. Centennial Review. pp.437-470.

hooks, bell. 1992. Black Looks: Race and Representation. Boston: South End Press.

Kamanzi, B. 2015. "Rhodes Must Fall” Decolonisation Symbolism - What is Happening at UCT, South Africa? The Postcolonialist. Available: http://bit. ly/36Apjz4 [accessed 29 March 2015].

Kros, C. 2015. Rhodes Must Fall: Archives and counter-archives. Critical Arts, 29(1):150-165. https://doi.org/10.1080/02 560046.2015.1102270
Lalu, P. 2015. What is the university for? Mail and Guardian, 1 November.

Lacan, J. 1977. Ecrits. A Selection. A. Sheridan (tr.). Tavistock: London.

Levinas, E. 1986. The Trace of the Other. In: M. Taylor (ed.), Deconstruction in Context. Chicago: University of Chicago Press.

Mamdani, M. 2012. Define and Rule: Native as Political Identity. Cambridge: Harvard University Press. https://doi.org/10.4159/ harvard.9780674067356

Mamdani, M. 2016. Africa's Postcolonial Scourge. Mail \& Guardian, 27 March.

Maldonado-Torres, N. 2007. On the Coloniality of Being. In: Cultural Studies, 21(2):240-270. https://doi. org/10.1080/09502380601162548

Marshall, C. \& Rossman, G.B. 1989. Designing qualitative research. Newbury Park, CA: SAGE Publications.

Modest, W. \& De Koning, A. 2016. Anxious politics in the European city: an introduction, In: Patterns of Prejudice, 50(2):97-108. https://doi.org/10.1080/00 31322X.2016.1161384

McNeil, M. 1993. Dancing with Foucault. In: C. Ramazanoglu (ed.), Up against Foucault: Explorations of Some Tensions between Foucault and Feminism. Routledge: London. pp.147-179.

Mignolo, W. 2009. Epistemic Disobedience, Independent Thought and DeColonial Freedom. In: Theory, Culture \& Society, 26(7-8):1-23. https://doi. org/10.1177/0263276409349275

Mouffe, C. 2005. On the Political. Routledge: Abingdon and New York. 


\section{SCHOLARLY ENGAGEMENT AND DECOLONISATION}

Mulvey, L. 1989. Visual and Other Pleasures. Hampshire \& London: Macmillan Press. pp.14-26. https://doi. org/10.1007/978-1-349-19798-9_3

Mupotsa, D. 2017. Being/Becoming an Undutiful Daughter: Thinking as a Practice of Freedom. In: R. Osman \& D.J. Hornsby (eds.), Transforming Teaching and Learning in Higher Education. London: Palgrave Macmillan. https://doi.org/10.1007/978-3-31946176-2_3

Ndlovu-Gatsheni, S. 2015. Decoloniality in Africa: A Continuing Search for a New World Order. The Australasian Review of African Studies, 36(2):22-50.

Nkopo, A.E. 2015. We Still Don't Belong Here. The Star. Available: http://bit.ly/312DJXG

Omarjee, N. 2016. South African Students Have Much to Teach Those Who Ignore Injustice, The Conversation. Available: http://bit.ly/2RVYX5d

Omarjee, N. 2018. Reimagining the Dream: Decolonising Academia by Putting the Last First. Leiden: Brill.

Piketty, T. 2015. Nelson Mandela Annual Lecture. Available: http://bit.ly/36BX5ns [accessed 3 October 2015].

Prasad, A. \& Pushkala P. 2002. Otherness at large: identity and difference in the new globalized organizational landscape. In: I. Aaltio \& A.J. Mills (eds.), Gender, Identity and the Culture of Organizations. London \& New York: Routledge. pp.57-71.

Ramazanoglu, C. (ed.). 1993. Up against Foucault: Explorations of Some Tensions between Foucault and Feminism. London: Routledge.
Smith, L.T. 1999. Decolonizing

Methodologies: Research and

Indigenous People. UK \& US: Zed Books.

Spivak, G., Landry, D. \& MacLean, G.M.

1996. The Spivak reader: Selected Works. London: Routledge.

Schwartz, Adria. 1998. Sexual Subjects: lesbians, gender and psychoanalysis. New York: Routledge.

Shuttleworth, R. 2004. Case Studies In Participant Observation. In: L. Hume \& J. Mulcock (eds.), Anthropologists in the Field. New York: Columbia University Press.

Soudien, C. 2011. Interrogating the nature of the 'universal' in South Africa's new educational order. Globalisation, Societies and Education, 9(3-4):323-336. https://doi.org/10.1080/14767724.2011.6 05318

Soudien, C. 2012. Becoming UWC: Reflections, Pathways and Unmaking Apartheid's Legacy. Social Dynamics, 38(2):352-357. https://doi.org/10.1080/0 2533952.2012.719110

Soudien, C. 2015. Nelson Mandela, Robben Island and the Imagination of a New South Africa. Journal of Southern African Studies, 41(2):353-366. https://doi.org/10 .1080/03057070.2015.1012915

Thiong'o, N. 2006. Decolonising the Mind: The politics of language in African Literature. Oxford: James Curry.

Wekker, G. 2016. White Innocence: Paradoxes of Colonialism and Race. Durham \& London: Duke University Press. https://doi.org/10.1215/9780822374565 


\section{CHAPTER 6 - Decolonising research methods}

Vally, S. \& Motala, E. 2014. Education, Economy \& Society. South Africa: UNISA.

Van Zoonen, L. 1994. Feminist Media Studies. London: SAGE Publications.
Wanelisa, X. 2017. Challenging Fanon: A Black radical feminist perspective on violence and the Fees Must Fall movement. Agenda, 31(3-4):96-104. https://doi.org/10.1080/10130950.2017. 1392786

Žižek, S. 2006. How to Read Lacan. London: Granta Books. 